\title{
Subsídios para o desenvolvimento de práticas pedagógicas promotoras da igualdade racial na educação infantil
}

\author{
Lucimar Rosa Dias* \\ Hédio Silva Jr.** \\ Maria Aparecida Silva Bento ${ }^{* *}$
}

Resumo: Este artigo é um dos produtos resultantes de um plano de cooperação técnica entre a Secretaria de Educação Básica (SEB/ COEDI/MEC) e a Universidade Federal de São Carlos (UFSCar), realizado em 2010. A execução foi compartilhada com o Centro de Estudos das Relações de Trabalho e Desigualdades (CEERT), tendo como uma de suas açóes a formação da Rede Nacional para a Igualdade Racial na Educação Infantil. O objetivo principal é oferecer subsídios para professores e gestores comprometidos com uma educação pautada na igualdade racial, ao mesmo tempo em que preenche uma lacuna em relação à Lei de Diretrizes e Bases da Educação - LDB, alterada pela Lei 10.639 de 2003 e pela $11.645 / 08$, que às vezes é entendida como não aplicável à educação infantil. Nossa pretensão é que o debate sobre esse tema possa agregar críticas e contribuições que reflitam com o máximo de fidelidade o acúmulo de professores, gestores, pesquisadores

* Professora da Universidade Federal de Mato Grosso do Sul. Mestre e doutora em Educação. Colaboradora do CEERT (Centro de Estudos das Relações de Trabalho e Desiguladades) e do MEC. E-mail: lucimar_dias@uol.com.br

* Diretor Executivo do CEERT e Diretor Acadêmico da Universidade Zumbi dos Palmares. Doutor em Direito do Estado pela PUC/SP, Ex- Secretario de Justiça do Estado de SP, autor de vários livros, dentre eles Discriminação racial nas escolas: entre as leis e as práticas. E-mail: hedsilva@uol.com.br

*** Diretora executiva do CEERT e doutora em psicologia. Autora de vários livros sobre relaçôes raciais no Brasil, dentre eles Cidadania em Preto e Branco: discutindo relaçôes raciais. E-mail: cibento@uol.com.br 
e ativistas políticos que se dedicam ao tema.

Palavras-chave: Igualdade Racial; Educação Infantil; Políticas Públicas; Práticas Pedagógicas.

\begin{abstract}
This article results from a technical cooperation between the Secretary of Basic Education (SEB/COEDI/MEC) and the Federal University of São Carlos (UFSCar), in 2010. The implementation included the Center for the Study of Labor Relations and Inequalities (CEERT). One of its actions is creation of the National Network for Racial Equality in Early Childhood Education. The main objective of this movement is to provide grants to teachers and administrators committed to an education based on racial equality, while it fills a gap in relation to the Law of Guidelines and Bases of Education (LDB), amended by Law $10.639 / 2003$ and the $11.645 / 2008$, which is sometimes perceived as not applicable to early childhood education. Our claim is that the debate on this theme can provide reviews and contribution that reflect as good as possible the experience of teachers, managers, researchers, and political activists dedicated to this subject.
\end{abstract}

Keywords: Racial Equality; Child Education; Public Policies; Pedagogical Practices.

\title{
Introdução
}

A revisão das Diretrizes Curriculares para a Educação Infantil no ano de 2009 reafirmou o que já constava de outras normativas sobre a necessidade de as instituições de atendimento às crianças pequenas assegurarem em sua proposta pedagógica o acesso às contribuiçôes dos povos negros em diferentes instâncias, de modo que se garanta o direito de todas as crianças, independentemente de seu pertencimento racial, de ter acesso a 
experiências que colaborem na construção de suas identidades positivamente. Este artigo pretende fornecer subsídios para os professores na forma de reflexões e proposições, no sentido de orientar a prática pedagógica realizada em creches e pré-escolas para efetivação de açôes que promovam a igualdade racial na educação infantil.

A produção deste documento é parte de um Plano de Cooperação Técnica entre a Secretaria de Educação Básica (SEB/ MEC) e a Universidade Federal de São Carlos (UFSCar), cuja execução foi compartilhada com o Centro de Estudos das Relações de Trabalho e Desigualdades (CEERT), tendo como uma de suas ações a formação da Rede Nacional para a Igualdade Racial na Educação Infantil.

O objetivo principal desse movimento é oferecer subsídios para professores e gestores comprometidos com uma educação pautada na igualdade racial, ao mesmo tempo em que preenche uma lacuna em relação à Lei de Diretrizes e Bases da Educação - LDB, alterada pela Lei 10.639 de 2003 e pela 11.645/08, que às vezes é entendida como não aplicável à educação infantil. $\mathrm{O}$ documento resulta de debates realizados em quatro seminários regionais em Belo Horizonte, Belém, Recife, Curitiba. Esses encontros foram concebidos e mobilizados com a participação direta dos Fóruns de Educação Infantil e MIEIB - Movimento Interfóruns de Educação Infantil do Brasil, e contaram com a presença da Coordenadora de Educação Infantil (COEDI/MEC); do CEERT e de especialistas de diferentes universidades brasileiras.

Pretende-se atender a uma necessidade das instituições de educação infantil, bem como das secretarias, conferida pela Coordenação Geral de Educação Infantil - COEDI/SEB/MEC, e a uma exigência da Resolução CNE/CEB 20/2009 que atribui ao MEC o papel de orientar os respectivos sistemas de ensino na implementação das DCNEI, especialmente o Art. $8^{\circ}$, inciso que exige das propostas pedagógicas de educação infantil "IX - o reconhecimento, a valorização, o respeito e a interação das crianças com as histórias e as culturas africanas, afro-brasileiras, 
bem como o combate ao racismo e à discriminação". Nossa pretensão é que o debate sobre esse tema possa agregar críticas e contribuições que reflitam com o máximo de fidelidade o acúmulo de professores, gestores, pesquisadores e ativistas políticos que se dedicam ao tema.

Nesse documento trataremos da igualdade racial tomando como referência o conceito de raça a partir de problematizações de alguns estudiosos (MUNANGA, 2004; GUIMARÃES, 1999) que têm nos ajudado a melhor compreender as hierarquias sociais construídas no trânsito entre passado e presente e no âmbito de diferentes formações socioculturais.

A percepção de que as diferentes esferas da vida social (economia, cultura, religião, educação etc.) permitem, antes de tudo, a observação dos distintos modos de como indivíduos e grupos se inserem diferencialmente nos processos de interação social e, consequentemente, são produtores de inúmeras formas de sociabilidade, um fato amplamente aceito na atualidade. Assim, o conceito sociológico de raça, que não se baseia em qualquer fundamento de caráter biológico, tem relação com a forma que socialmente algumas características fenotípicas inatas são apropriadas discursivamente para fixar diferenças entre os sujeitos. Outro aspecto importante é explicitarmos como entendemos a diversidade.

Reflexões de Silveira (2002) realçam as armadilhas conceituais e os riscos da construção de indicadores "genéricos" de diversidade, suficientemente elásticos para comportar todas as modalidades de discriminação, tanto quanto para omitir ou secundarizar a discriminação de natureza étnico-racial.

No Brasil, o debate sobre pluralidade cultural e educação vem enfatizando uma educação para a diversidade. Entretanto, não se pode perder de vista que o mito da democracia racial brasileira propaga a ideia de uma eficaz integração de todos os grupos étnico-raciais da população e que este discurso, que oculta as desigualdades, permanece atuante (SILVEIRA, 2002, p. 08). 
Convém destacar que o termo diversidade, utilizado em normas, documentos e estudos referentes à educação escolar, normalmente é entendido como sinônimo de variedade, pluralidade e diferença. A diversidade é frequentemente associada às línguas e linguagens, culturas, cor da pele e outras características físicas. Segundo Muniz Sodré (2007), diversidade remete também à existência de valores atribuídos a determinadas aparências, gerando estigma, estereótipo, preconceito e discriminação, ou seja, pressupõe julgamento de valor. O diverso, o diferente, é definido a partir da comparação com o que é considerado "a referência", "o universal", que, por ser "modelo", é considerado e se considera superior.

Diversidade trata dos afetos e das atitudes. Está no território da aceitação do que é considerado "diferente". Diversidade remete à imediatez, à proximidade. Trata da convivência entre grupos humanos com diferentes histórias, diferentes infâncias, trajetórias, culturas e linguagens. Essa convivência é fundamental no que diz respeito à identidade: a constituição da pessoa invariavelmente baseia-se na convivência e no contraste com os outros.

A diversidade, no entanto, pode ser utilizada para relativizar o peso da luta contra a discriminação e pela promoção da igualdade de direitos. Por isso, o conceito de diversidade deve nos remeter a ações concretas que visem à inclusão, permanência e desempenho de todos no sistema educacional e, particularmente, dos que sofrem processos de desvalorização. A nosso ver, é necessário que ao tratar a diversidade como uma dimensão imprescindível das políticas educacionais sejam considerados três eixos.

O primeiro deve ser de estímulo à identificação e supressão de quaisquer práticas institucionais incompatíveis com a valorização da diversidade, bem como a eliminação de fontes de discriminação direta ou indireta no ambiente educativo, seja nos materiais didáticos ou na formulação das políticas de formação de professores. O segundo eixo deve ser o de adoção de orientações e normas escritas voltadas para a valorização da diversidade, tendo como objetivo último a inscrição de tal política como um valor 
perene na cultura institucional dos sistemas e redes de ensino. $\mathrm{E}$, por último, o estabelecimento de objetivos e indicadores que possibilitem o monitoramento do impacto e da eficácia da política de valorização da diversidade no ambiente educativo.

Quando a diversidade é abordada por meio desses eixos, certamente serão estabelecidas medidas concretas para a promoção da igualdade, possibilitando a inclusão social de crianças, homens e mulheres prejulgados em função de sua cor, raça, etnia, origem, sexo, deficiências, idade, credo religioso ou orientação sexual. Tratando-se de educação, não podemos mais aceitar que as políticas educacionais, particularmente as voltadas para crianças de 0 a 5 anos, se omitam frente à responsabilidade de promover uma educação igualitária pressuposta em documentos oficiais. Por isso, sem desconsiderar as outras dimensões da diversidade e da igualdade, nos centraremos em pensar como as práticas pedagógicas da educação infantil poderão incidir em melhoria da qualidade da educação oferecida a todas as crianças, garantindo novas práticas àquelas que vivenciam situações de preconceito e discriminação racial no ambiente da educação infantil.

Rosemberg (1991), a partir de seus estudos sobre a expansão dessa etapa educacional, apontou que a baixa qualidade de sua oferta tem afetado, especialmente, as crianças negras. Documento publicado em 2010, pelo Fundo das Nações Unidas para a Infância (Unicef), apresentou dados que evidenciam a relação entre raça/etnia, pobreza e frequência à educação infantil. No Brasil, dos 57 milhões de crianças e adolescentes, 31 milhões são de crianças negras e 140 mil são indígenas. Vinte e seis milhões de crianças e adolescentes brasileiros são originários de famílias de baixa renda, dentre elas, $56 \%$ são crianças negras, o que corresponde a 17 milhões. No que diz respeito ao acesso à escola, das 530 mil crianças de 7 a 14 anos que estão fora da escola, 330 mil são negras, contra 190 mil brancas, sendo as outras de outros grupos étnicos.

A esses dados, acrescentam-se os divulgados no $2^{\circ}$ Relatório Anual das Desigualdades Raciais no Brasil: 2009-2010, 
que são igualmente preocupantes quanto à situação das crianças negras. O relatório indica que em 2008 84,5\% das crianças negras de até 3 anos não frequentavam creches e 79,3\% das crianças brancas sim. Em relação às crianças negras de 6 anos, $7,5 \%$ estavam fora de qualquer tipo de instituição educacional, enquanto $4,8 \%$ das crianças brancas estavam nesta situação e, por fim, somente $41,6 \%$ das crianças negras de 6 anos estavam no sistema de ensino seriado comparado a $49 \%$ das crianças brancas.

Pelos dados apresentados, constatamos que a desigualdade na educação infantil é permeada pelo pertencimento racial e seu rompimento é certamente desafiador, pois ao lado dessa questão existem outras dificuldades a serem vencidas na consolidação de um atendimento de qualidade às crianças de 0 a 5 anos. A formação dos professores, a oferta de equipamentos adequados, o currículo, a participação da família, o acesso etc. Diante desse quadro, há uma tendência a secundarizar a discussão sobre a igualdade racial. Porém, ao tratarmos desse tema não retiramos o foco desses problemas, ao contrário, pensar como as desigualdades em relação às crianças negras de 0 a 5 anos podem ser superadas é parte da política universal de ofertar com qualidade a educação infantil.

Embora já saibamos que o acesso à educação infantil tem extrema importância no desenvolvimento de uma criança e que nos primeiros anos de vida as interações vividas são fundamentais na constituição de suas identidades, o pertencimento racial tem sido largamente negligenciado nessas consideraçôes e pouco tem se produzido no sentido de compreender como a ocorrência da desigualdade racial na sociedade brasileira incide sobre a educação oferecida à criança pequena e qual tem sido o papel do Estado como ente protetor dessa criança.

Nesse sentido, acreditamos que a efetivação da igualdade racial deve ser parte integrante da proposta pedagógica das instituições de educação infantil, concretizando-se nas práticas pedagógicas desenvolvidas cotidianamente e tendo como eixos norteadores as interações e as brincadeiras, articuladas às 
experiências e aos saberes trazidos pelas crianças, sejam as de creche ou as da pré-escola.

Para colaborar na construção de uma política educacional que considere a igualdade racial apresentamos neste documento algumas reflexões fruto, como já dissemos de muitos debates sobre o tema. Ele está dividido em duas partes: a primeira trata da dimensão legal e histórica situando a igualdade racial e a educação infantil; a segunda apresenta alguns tópicos no sentido de subsidiar gestores e professores no processo de construção de propostas pedagógicas que considerem a dimensão da igualdade racial na educação infantil. Nosso pressuposto ao tratar do desse tema é que estamos nos referindo ao patrimônio cultural, artístico, científico e tecnológico, aos quais todos os cidadãos brasileiros têm direito ao acesso.

\section{O que é promoção da igualdade racial na educação infantil?}

Ao reconhecer creches e pré-escolas como instituições educativas, superando o escopo assistencialista predominante até 1988, a Constituição Federal atribuiu à educação infantil uma identidade especial e estratégica na formação dos cidadãos brasileiros definindo-a como primeira etapa da educação básica. A natureza da educação infantil e o princípio da autonomia assegurado pela Constituição e pela Lei de Diretrizes e Bases n ${ }^{\circ}$ 9394/96 tornam especialmente desafiadora a tarefa de desenhar propostas que auxiliem gestores, professores, profissionais de apoio e comunidades a instituírem nas creches e pré-escolas um ambiente de vivências e experiências que possibilitem a aprendizagem da diversidade étnico-racial como parte integrante dos conhecimentos necessários para a construção de uma sociedade democrática e igualitária. 
Trata-se de empreendimento que exige atenção para alguns aspectos aparentemente óbvios, mas quase sempre desconsiderados nas propostas pedagógicas e nas práticas em educação infantil.

O primeiro é que nosso país conforma uma rica geografia de identidades étnico-raciais, culturais e religiosas, de sorte que segundo o último recenseamento geral a população negra representa mais da metade dos brasileiros, há cerca de 250 etnias indígenas, sem olvidarmos do pluralismo religioso, dos cidadãos que não professam crença religiosa, das crianças e adolescentes portadores de deficiências e daquelas que provêm de famílias cujo núcleo difere do antigo padrão homem/mulher.

Vale lembrar, por exemplo, que a referida diversidade implica a afluência para creches e pré-escolas de uma variada gama de crianças com tipos estético-corpóreos e culturais, elementos constitutivos da identidade de bebês e crianças pequenas, que sob nenhuma hipótese podem ser ignorados, subestimados, discriminados ou negligenciados pelos educadores.

$\mathrm{O}$ outro fator relaciona-se com um pressuposto da educação escolar, segundo o qual "A aprendizagem começa com o nascimento" (Art. 50 UNESCO, 1990), o que significa dizer que desde a nascença, e mesmo durante a gestação, a criança está imersa em práticas sociais que influenciam vigorosamente suas atitudes e valores, tanto quanto conhecimentos.

\section{Interações na educação infantil e promoção da igualdade racial - discussão necessária?}

Desde o final da década de 80, pesquisas vêm demonstrando o impacto silencioso da linguagem, dos símbolos e das atitudes sociais na reprodução de estereótipos e preconceitos que alcançam os indivíduos ainda em tenra idade.

Trinidad (2011), Oliveira (2004), Dias (1997, 2007), Cavalleiro (1998) e Godoy (1996), dentre outros, apontam em 
suas pesquisas que interações vividas no cotidiano da educação infantil envolvem o pertencimento racial, embora nem sempre pautadas por questões conflituosas, sendo, porém, inegável a presença de um extenso repertório preconceituoso que se estabelece nas relações entre adultos e crianças. Entre as professoras, é comum o tratamento distinto dado às crianças, com tendência para a valorização das brancas e desvalorização das negras. Professoras da educação infantil simplesmente não penteiam o cabelo crespo das crianças negras, alegando não saberem como fazê-lo; classificam como "difícil" uma criança negra pelo fato de ela "sempre querer fazer tudo" e esse mesmo atributo é usado como positivo ao se referir a uma criança branca, "fácil de lidar" (SILVA, 2002). Oliveira e Abramowicz (2010, p. 209-210), ao relatarem a pesquisa realizada em uma creche no interior de São Paulo, constatam que:

[...] Outro estereótipo também corrente na creche é que as travessuras sempre estavam associadas às crianças negras, pois elas eram as "vilãs" da história. Na creche, em toda sala havia um "furacão". O "furacão" pode ser conceituado, de acordo com as professoras, como "um menino bastante terrível, que se movimenta o tempo inteiro, que estraga as brincadeiras, que também bate nos colegas", ou seja, o vilão da sala, com o seguinte detalhe: ele é negro. Toda sala tinha um "furacão negro" (OLIVEIRA, ABRAMOWICZ, 2010, p. 209-210).

Outro exemplo de como a discriminação e o preconceito atingem os bebês, foi registrado por Dias (2007) em depoimentos de professoras que afirmam perceber tratamentos diferenciados para bebês negros e bebês brancos:

Na educação infantil, a gente já sentiu essa questão da diferença do tratamento dos profissionais em relação à criança negra e à criança branca. Essa questão do estereótipo. Do modelo único de beleza, que é branco, loiro dos olhos claros ou verdes. Essa questão é muito forte na educação infantil. As crianças negras não têm tanto colo, chamego, aconchego como tem a criança branca (Educadora Mame, de Campinas - entrevista concedida em 13/09/06). [...] Quando aparece um bebê Johnson na escola, todo mundo [diz]: - "ai que lindo!" Um bebê Johnson que eu falo é um menino loiro, de olho azul, bem gordo. Gordinho, bem fofo. Então esse bebê passeia pela escola inteira. Ele passeia com a monitora 
do outro setor, com a diretora. Como se sente a criança que nunca sai? Educadora Aminata, de Campinas - entrevista concedida em 12/09/06 (DIAS, 2007, p. 42).

Os depoimentos evidenciam que há um tipo de bebê que tem mais chances de receber maior atenção em instituições de educação infantil: "A professora revela, com esse exemplo, como o imaginário brasileiro é influenciado pela mídia e como estamos permeados pela ideia do belo como branco" (Idem, p. 42).

Estudos levados a cabo em outros países atestam que crianças começam a perceber as diferenças raciais na faixa etária dos 3 aos 5 anos de idade e, com o tempo, passam a julgá-las em conformidade com o contexto em que estão inseridas, podendo expressá-las com propósito mesmo não calculado de desvalorizar o outro.

Convém recordar que a estrutura social brasileira na qual se inserem as creches e pré-escolas é comprovadamente desigual e discriminatória, nomeadamente do ângulo étnico-racial, pelo que seria uma ingenuidade, para dizer o mínimo, presumir-se que tais instituições estariam imunes ao fenômeno da discriminação racial, não refletindo em nenhuma escala seus efeitos deletérios, sobretudo, quando atingem bebês e crianças.

\section{Por que promover a igualdade racial na educação infantil?}

É crescente nos últimos anos a preocupação com formulações conceituais e normativas capazes de orientar a atuação de professores e gestores no tratamento da igualdade racial na educação infantil. Tais formulações, no entanto, geralmente baseiam-se em um equívoco conceitual que minimiza, empobrece e esvazia o desempenho da educação infantil, qual seja a ideia de que se deve adotar um posicionamento meramente reativo, de repressão da discriminação e do preconceito. 
Algumas propostas endereçadas à educação infantil frequentemente empregam expressões como "posicionar-se contra discriminação", "refletir sobre a injustiça dos preconceitos", "denunciar qualquer forma de discriminação", "não ter preconceito", "combater preconceitos" etc. É certo que a própria Constituição Federal e também o Estatuto da Criança e do Adolescente determinam que a criança deva ser colocada a salvo de toda "[...] negligência, discriminação, crueldade e opressão" [...](Constituição Federal - CF, art. 227, caput; ECA, Lei 8.069/90, art. $5^{\circ}$ ).

Nesse sentido, a educação escolar como dever do Estado precisa fazer muito mais do que reprimir a discriminação - ela pode e deve educar crianças e adultos a construírem uma socie dade igualitária reconhecendo e valorizando a diversidade étnico-racial como constitutivas da identidade nacional e como exigência para a construção de uma sociedade justa, igualitária e democrática.

A Convenção sobre os Direitos da Criança estabelece no Art. 29:

1. Os Estados Partes reconhecem que a educação da criança deverá estar orientada no sentido de:

$[\cdots]$

c) imbuir na criança o respeito aos seus pais, à sua própria identidade cultural e ao seu idioma e seus valores aos valores nacionais do país em que reside, aos do eventual país de origem e aos das civilizações diferentes da sua;

d) preparar a criança para assumir uma vida responsável numa sociedade livre, com espírito de compreensão, paz, tolerância, igualdade de sexos e amizade entre todos os povos, grupos étnicos, nacionais e religiosos e pessoas de origem indígena.

À luz de formulaçôes como essa fica evidente que a pergunta "o que podemos fazer para reprimir a discriminação no espaço escolar?", subjacente à concepção reducionista, deve ser substituída por "o que podemos fazer para erradicar o racismo, a discriminação e o preconceito da sociedade brasileira?”. Dito 
de outro modo, como podemos otimizar o escopo didático e social dos projetos e práticas educativas de modo que valores e atitudes sejam orientados para a formação de cidadãos aptos a conviverem naturalmente com a diversidade humana?

O enfrentamento de tais indagações demanda que a educação infantil, como de resto a educação escolar como um todo, seja considerada a partir de dois ângulos distintos e complementares: o primeiro como espaço dentro do qual deve ser assegurada a interação respeitosa e positiva com a diversidade humana, adequando-se os espaços físicos, materiais didáticos e paradidáticos e formando professores, gestores e funcionários para serem agentes de promoção da igualdade racial; o segundo ângulo situando a educação infantil como contexto de transformação social, no sentido em que educa a infância para valorar positivamente a diferença, dissociando diferença de inferioridade de tal sorte que, a médio e longo prazo, o preconceito e a discriminação sejam erradicados da sociedade.

Isto é, não basta que a educação infantil não seja ela própria uma fonte de discriminação, cabendo-lhe também garantir uma cultura de respeito recíproco e de convivência harmoniosa entre todos os grupos étnico-raciais, como também culturais e religiosos. É imprescindível a consideração da educação infantil como um direito, ao qual a legislação nacional e a internacional atribuem ideários e objetivos que não podem ser ignorados por gestores, professores, profissionais de apoio e comunidade em geral.

\section{Aspectos legais e a dimensão da igualdade racial e suas proposições}

A Constituição Federal fixa três objetivos nucleares para a educação, quais sejam: garantir o pleno desenvolvimento da pessoa, o preparo para o exercício da cidadania e a qualificação para o trabalho (Constituição Federal, art. 206). "A educação infantil, primeira etapa da educação básica, tem como finalidade 
o desenvolvimento integral da criança até seis anos de idade, em seus aspectos físico, psicológico, intelectual e social, complementando a ação da família e da comunidade” (Art. 29 da LDB). Cristalina, incisiva e eloquente, a Lei de Diretrizes e Bases da Educação assim se refere a um dos principais objetivos da educação infantil.

No plano das normas internacionais, há poucos anos o Brasil ratificou a Convenção sobre a Proteção e Promoção da Diversidade das Expressões Culturais, que classifica a identidade cultural como direito fundamental da pessoa humana. No mesmo sentido, prescreve a Declaração Universal sobre a Diversidade Cultural que "a diversidade cultural é fator de existência intelectual, afetiva, moral e espiritual satisfatória” (Art. $\left.3^{\circ}, 2002\right)$. Note-se que a proteção contra a violência psíquica, o direito à identidade cultural e a preparação da criança para assumir um espírito de compreensão, paz e amizade entre os grupos étnicos, referidos acima, não constituem um plexo caótico de admoestações, destituído de valor jurídico, mas sim uma previsão normativa, à qual a política educacional deve observância obrigatória.

Com isso, queremos destacar que o pleno desenvolvimento da pessoa, no contexto de sociedades plurirraciais e multiculturais como a nossa, vincula-se à capacidade dos sistemas de ensino dialogarem, valorizarem e protegerem os marcos culturais formadores da nacionalidade, sem o que se compromete não o interesse de um ou outro grupo particular, mas a própria qualidade da educação. Vale realçar ainda a existência de normas constitucionais que prescrevem textualmente a valorização da diversidade étnica (CF, art. $215, \$ 3^{\circ}$ ) e da identidade dos diferentes grupos formadores da sociedade brasileira (CF, art. 216, caput).

Ancoradas nesse preceito, as Diretrizes Curriculares Nacionais para a Educação Infantil estabelecem, no art. $8^{\circ} \$ 2^{\circ} \mathrm{II}$, que se deve "reafirmar a identidade étnica e a língua materna como elementos de constituição das crianças", isso precisa estar evidenciado nos projetos político-pedagógicos das instituições de educação infantil, garantindo às crianças acesso aos diversos 
processos de conhecimento e aprendizagem (CNE, Resolução n. 05, 17.12.09). Acrescente-se ainda que a Constituição Federal refere apenas a duas experiências de aprendizagem curriculares previstas indistintamente para todos os níveis de ensino, quais sejam para "o ensino fundamental regular será ministrado em língua portuguesa, assegurada às comunidades indígenas também a utilização de suas línguas maternas e processos próprios de aprendizagem" (CF, art. 13 e $210, \$ 2^{\circ}$ ) e "o ensino da História do Brasil levará em conta as contribuições das diferentes culturas e etnias para a formação do povo brasileiro" (CF, art. 13 e 210). Trata-se de preceito regulamentado inicialmente no art. 26 da LDB, situado no Capítulo II, referente à Educação Básica e que numa interpretação ampliada alcança, portanto, a educação infantil.

Alterações posteriores sofridas pela LDB acrescentaramlhe dois artigos relacionados àquele, o art. 26-A e o art. 79-B, os quais preveem no ensino fundamental e no ensino médio $\mathrm{O}$ estudo da história e cultura afro-brasileira e indígena e a inclusão no calendário escolar do dia 20 de novembro como Dia Nacional da Consciência Negra. Está em questão, portanto, não uma especificidade ou tema de interesse de negros ou indígenas, algo secundário, incidental, marginal à gestão da educação: sem o enfrentamento dessa problemática a política educacional continuará ignorando um dos pilares jurídico-políticos da educação brasileira.

\section{Qual é o papel dos professores e dos gestores na produção de práticas pedagógicas que promovam a igualdade racial na educação infantil?}

Sem o engajamento, o aprendizado e o comprometimento pessoal dos professores não é possível o Brasil construir uma política educacional igualitária, que eduque crianças e jovens para valorizarem a diversidade e construírem uma sociedade em que a democracia racial seja um fato e não um mito. 
Uma política educacional igualitária quer significar mais do que o ensino da História e da Cultura Afro-Brasileira no ensino fundamental e no ensino médio. Ela começa na educação infantil e precisa perpassar o sistema educacional como um todo. A formação de professoras e professores, os projetos políticopedagógicos, a política de materiais pedagógicos, o financiamento da educação, o controle social da política educacional, enfim, o conjunto de marcos legais, valores e práticas pedagógicas e atores que dia a dia implementam o serviço público republicano denominado educação.

Mas é possível pensar que dentre esses tantos fatores há um determinante, estratégico, condição sine qua non para o sucesso da empreitada: o engajamento profissional dos professores e gestores. Dizemos engajamento porque a temática da educação igualitária, ou do papel da educação escolar na desconstrução dos estereótipos e preconceitos propagados pela educação social, requer mais do que concordância com leis ou com declaraçôes solenes de valorização da diversidade. Requer atitude, compromisso e grandes e pequenos gestos no cotidiano das creches, pré-escolas e escolas.

Ao tratarmos desse assunto, estamos quase sempre tratando de nós mesmos, da nossa constituição como pessoa, das narrativas que no dia a dia realimentam ideias pré-concebidas que a sociedade produz e a educação escolar tende a reproduzir. Por isso, dizemos que não basta concordar: é preciso acreditar na ideia de que a educação pode sim transformar valores, ideias e participar da construção de um mundo em que nossas crianças não sintam vergonha de seu corpo ou da história de seu povo porque descendem de africanos ou indígenas. Nesse sentido, a etapa de desenvolvimento da identidade racial em que se encontra o professor, suas concepções, sentimentos e afetos, sobre si próprio e sobre o outro, impactam também a formação da identidade da criança sob seus cuidados. 


\section{O que as experiências já realizadas nos ensinam? Alguns pressupostos}

Por mais óbvio que nos possa parecer, a primeira e mais básica proposição é jamais silenciar ou omitir-se diante desse tema. Tratando-se do tema da discriminação racial, o silêncio e a omissão nunca operam como elementos neutros - eles sempre contestam e reforçam a violência decorrente daquelas práticas. Igualmente verdadeiro é que há ações que devem ser evitadas, tais como tratar desse tema apenas em dias especiais; retratar o continente africano como se fora um país (trata-se de um continente que tem 53 países); representar os africanos de modo estereotipado, com tangas, lanças e associados a animais selvagens.

Assim como já acumulamos conhecimento para sabermos como a questão da igualdade racial não deve ser abordada, também já existe uma produção considerável que nos indicam caminhos adequados para esse tratamento. Vejamos esquematicamente algumas proposições:

- Incluir a temática racial no currículo da educação infantil, de modo que ela permeie todo o cotidiano escolar e não somente projetos isolados ou tome como base conflitos.

- Abordar a temática por meio de explicações sobre as diferenças, valorização e admiração das características físicas das crianças, tais como o cabelo, a cor da pele, propiciando desse modo vivências que as crianças, principalmente as negras, possam experienciar a autoestima e, assim, sentirem-se valorizadas.

- Garantir a presença de profissionais pertencentes aos grupos discriminados não apenas em funções subalternas, no quadro de pessoal da instituição.

- Constar nos documentos da instituição a preocupação em assegurar tratamento igual para todas as crianças.

- Contemplar todos os grupos étnico-raciais nos materiais didáticos adquiridos. 
- Apresentar a diversidade racial nos diferentes espaços: biblioteca, parquinho, sala de atividades, refeitório e outros espaços da instituição.

- Contemplar a diversidade racial nos materiais de comunicação utilizados pela escola.

- Realizar cursos de formação de professores em que essa questão esteja explicitamente garantida.

- Envolver sempre as famílias nas atividades desenvolvidas com essa temática, considerando seus saberes.

A prática pedagógica deve ser capaz de garantir a valorização da cultura negra, bem como a participação de toda comunidade escolar (professores, diretores, funcionários e famílias) nas atividades realizadas no ambiente escolar sobre a temática racial, a fim de que toda comunidade se conscientize e se engajem no trabalho com a temática.

\section{Como podemos avançar na promoção da igualdade racial?}

Tais proposições estão pautadas em pesquisas realizadas no âmbito das universidades, mas também em experiências realizadas por professores de diferentes regiões do Brasil, muitas delas identificadas nas cinco edições do Prêmio Educar para a Igualdade Racial, realizado pelo CEERT. O acúmulo dessas experiências resulta em conhecimentos que, a seguir, serão apresentados no sentido de colaborar para a construção de propostas pedagógicas nas quais a dimensão da igualdade racial esteja contemplada, fazendo parte intrínseca das experiências de aprendizagem das crianças nessa etapa da educação básica.

A nossa experiência de muitos anos nas ações de formação de professores, as pesquisas acadêmicas realizadas e muitos projetos desenvolvidos ou acompanhados por nós nos permitem apresentar possibilidades de práticas a serem desenvolvidas. Algumas irão iluminar práticas com bebês ou com crianças bem pequenas, porém não muitas, pois é uma fase com poucas 
pesquisas e experiências. Outras se aplicam às crianças maiores. O que se espera é que os tópicos sirvam para instigar gestores, professores e famílias a pensarem propostas pedagógicas que incluam a dimensão da igualdade racial.

\section{Experiências voltadas ao conhecimento e cuidado de si, os cuidados do corpo}

O corpo é uma das vias mais importantes na interação com os bebês. É por meio do corpo, do toque e do olhar que eles sentem o acolhimento. Nos berçários das instituições, os momentos do banho, da mudança de fraldas, é lugar de troca de toques, de energia, de sentimentos, por isso eles são especiais para as crianças. $\mathrm{O}$ bebê percebe a si próprio por meio do adulto que o toca, do gesto carinhoso que recebe ou das expressões de raiva e indiferença do adulto que com ele convive. Os bebês, nesse contato diário, se percebem queridos ou não em diferentes momentos dessas interações. A hora da alimentação, de dormir, as cantigas que lhe são apresentadas, as imagens, os movimentos, tudo isso é perpassado pelos valores do adulto que está nessa relação de educar/cuidar.

Esse processo vai construindo a autoconfiança da criança e dando-lhe informações corporais, visuais e de oralidade sobre ela e sobre os outros. É importante, portanto, que a professora observe seu modo de atuar nesses momentos. Reflita sobre quem é o primeiro a receber esses cuidados. É sempre a mesma criança? Por qual motivo? Como olha para cada uma das crianças quando as está alimentando ou dando banho? Como as chama? Dá-lhes apelidos? Quais? Por quê? Como toca seus cabelos? Penteia-os? $\mathrm{O}$ que lhes diz?

Essas interações fornecem às crianças referências positivas ou negativas sobre si mesmas, sobre "seu jeito de ser", sobre seus cabelos, a cor de sua pele, seus olhos. O "eu" precisa do "outro" para tomar consciência de si, e, nessa relação, dimensões cognitivas e afetivas caminham juntas. As professoras, nessa interação, 
estarão mediando as interpretações entre o que os pares (as outras crianças) pensam e o que cada criança pensa de si mesma.

A tarefa da professora deve incluir o diálogo pedagógico. Falar com um bebê enquanto lhe dá banho, troca as fraldas ou o faz dormir dizendo-lhe: como são lindos seus olhos - sejam eles azuis, pretos, amendoados, "puxadinhos" ou de qualquer outro formato e cor; como sua pele é macia, seja branca nas suas infinitas variações ou negra em suas múltiplas possibilidades, ou ainda como seus cabelos são gostosos de serem acariciados, sejam crespos ou lisinhos, é uma das formas de construir um autoconceito positivo na criança. Uma das experiências de aprendizagem bastante interessantes para serem trabalhadas com as crianças é o reconhecimento progressivo do próprio corpo e das diferentes sensações e ritmos que produz, bem como o respeito às características pessoais relacionadas ao gênero, raça, etnia, peso, estatura etc. Portanto, ao desenvolver esse tipo de atitude a professora está assumindo o seu compromisso profissional com práticas promotoras da igualdade.

\section{Experiências que possibilitem a construção do respeito, da solidariedade e da percepção da diversidade racial e cultural brasileira}

Os modos de andar, correr, arremessar, saltar resultam das interações sociais e da relação dos seres humanos com o meio e são movimentos cujos significados têm sido construídos em função das diferentes necessidades, interesses e possibilidades corporais humanas presentes nas diferentes culturas em diversas épocas da história. Os seres humanos movimentam-se instintivamente, mas não só, pois graças à capacidade humana de refletir sobre seus próprios atos, muitos movimentos foram transformados em simbologias adquirindo significados particulares para cada grupo ou comunidade.

Uma prática promotora da igualdade vai incluir nas suas atividades experiências que possibilitem às crianças conhecerem as muitas possibilidades de movimentos que os diferentes grupos 
construíram, a produção da musicalidade, nos modos como se relacionam com seus corpos. Com os bebês, podem ser realizadas atividades nas quais estejam presentes brincadeiras do patrimônio cultural afro-brasileiro, que é bastante rico em atividades lúdicas nas quais as crianças irão interagir com a sonoridade, com as cores, com os movimentos.

Nessas experiências de aprendizagem, reside uma rica oportunidade para que professoras trabalhem com as crianças os gestos que servem como meios de comunicar algo e suas possibilidades distintas, dependendo da cultura. Também é pertinente o estudo de danças produzidas em diferentes culturas ou mesmo de danças existentes no Brasil que agregaram elementos das culturas negras, indígenas, europeias, asiáticas etc. Bebês e crianças ainda bem pequenas gostam de dançar ao som de músicas que podem ser oriundas de variados grupos étnicos e raciais, sendo a capoeira um universo muito importante, pois conjuga a música, a dança, o jogo e ainda o jongo e o maculelê, dentre outros possibilitam a exploração das múltiplas linguagens e do conhecimento da diversidade cultural.

Para as crianças maiores, o universo dos jogos, as brincadeiras, a dança e as práticas esportivas revelam, por seu lado, a cultura corporal de cada grupo social, constituindo-se em atividades privilegiadas, nas quais o movimento é aprendido e significado. Possibilitar às crianças contato com esse universo de dança, ritmos, prática esportiva será bastante instigante e cheio de novidades. Do mesmo modo podemos pensar as vivências relativas às músicas. Todos os grupos humanos cantam, então, por que não proporcionar às crianças desde muito cedo o encontro com músicas de vários lugares do mundo, estilos, línguas e rituais? As crianças são muito curiosas, como sabemos. Elas ouvem e querem saber o que está sendo dito, ou por que estão cantando daquele jeito etc. Querem repetir, refazer, fazer diferente. São momentos oportunos para introduzir as percepções de que todos os povos têm músicas para diferentes situações, nascimento, morte, casamento e aniversário, entre outras festividades. Investigar 
isso será uma caminhada estimulante. Também é o momento ideal para questionar músicas e brincadeiras musicais que sejam preconceituosas. Muitas delas estão mantidas nas escolas sob o argumento de que fazem parte do folclore brasileiro, mas sabemos que a sociedade brasileira produz e reproduz o racismo, por isso, temos que, inclusive, reconstruir coisas do nosso folclore, é por isso que somos sujeitos históricos.

Os bebês adoram cores e movimentos e podemos mostrar a eles imagens deles próprios, de outras pessoas, garantindo que os bebês negros serão contemplados nesse universo; eles podem brincar com panos de estampas africanas e tocar instrumentos de origem africana. Ampliar o repertório dessas crianças por meios imagéticos que lhes familiarizem com as referências culturais que favoreçam o rompimento do etnocentrismo é uma forma estimulante de trabalhar os movimentos, desenvolver a linguagem e definir outro lugar para a cultura africana no ambiente da educação infantil.

Com as crianças maiores, podem surgir dessas experiências de aprendizagem projetos e pesquisas sobre lugares do continente africano, tipos de dança e música, rituais, produção de instrumentos musicais, enfim, muita ação e aprendizagem com a música na educação infantil é possível, o fazer musical poder ser também, aprendizagens sobre a história dos negros brasileiros e da África.

Todos os povos representam artisticamente sentimentos, desejos, fatos ou ideias, que fazem parte de um determinado momento histórico de suas vidas. No trabalho com as artes visuais é importante proporcionar às crianças o contato com os mais variados tipos de manifestações artísticas, modelagem, esculturas, instalações e telas, entre outros. Elas devem aprender a apreciar a arte já produzida e serem estimuladas a produzir também a sua arte.

É uma rica oportunidade de apresentar para as crianças a produção das artes visuais dos povos africanos e indígenas. Elas são riquíssimas e ampliarão bastante a concepção das crianças sobre quem faz arte. A ideia de que a população negra, brasileira 
e africana produz artes plásticas ainda é muito restrita. Sempre que vemos alguém falar da arte negra, a pessoa está se referindo à capoeira, à comida ou a alguma coisa do tipo e lhes são apresentados apenas pintores europeus.

Faz-se necessário ampliar esse universo. Sugerimos que em todos os níveis da educação infantil, ao trabalhar as experiências de aprendizagem relacionadas à arte, as crianças possam conhecer os "fazeres artísticos" de diferentes povos, com destaque para os povos negros, sendo postas sempre a se perguntarem como e por que esses povos produzem arte, pois tais perguntas permitirão que elas se aproximem de histórias, crenças e valores dos grupos estudados.

Possibilitar às nossas crianças oportunidade de conhecer os modos de representar o mundo e os sentimentos de diferentes povos, significa construirmos com elas a concepção de igualdade e solidariedade entre os seres humanos na pluralidade social.

Os bebês e as crianças pequenas sentem-se atraídos pelo novo. Por isso, é uma ótima oportunidade de disponibilizar brinquedos e ambientes em que eles possam se relacionar com o patrimônio cultural brasileiro, familiarizando-os com os repertórios de origem afro-brasileira.

\section{Experiências que possibilitem a construção da identidade de si e do outro}

A construção da identidade ocorre a partir do diálogo com os outros. O "eu” precisa deles para poder tomar forma e consciência de si mesmo. Dessa forma, o processo de construção de identidade é dialético, assenta-se em idas e vindas, em conflitos e tensões. O outro é produto de muitos outros que o habitam, com seus valores, crenças, características de classe social, conhecimentos (ROCHA, KRAMER, 2011). "Cada eu é resultado de todos os outros que o formaram" (Ibid, p. 73). Assim, identidade remete à convivência, à relação com o outro. A identidade tem sede em um corpo (BENTO, 2002): o nosso corpo. A maneira como nos sentimos com nosso corpo interfere na construção de 
nossa identidade e autoestima. Um corpo estigmatizado, que sempre gera sentimentos de mal-estar devido às discriminações sofridas nas relações sociais cotidianas, não gera um autoconceito e uma autoimagem positivos. De outro lado, para Janet Helms (1990), identidade racial remete ao grupo maior, ao coletivo, e é, "acima de tudo, um sentimento coletivo ou grupal baseado em uma percepção de estar compartilhando uma herança racial comum com um grupo racial particular [...] é um sistema de crenças que se desenvolve em reação a diferenciais percebidos no pertencimento a grupos raciais” (BENTO, p. 2002).

Identidade racial exprime o sentido de pertinência dos membros ao seu grupo específico e reflete a forma pela qual um grupo social, com mais poder, define aqueles grupos com menos poder, colocando-os à parte e limitando sua participação (TEIXEIRA, 1992). Ou seja, identidade racial remete à desigualdade e à hierarquização entre os grupos. A identidade racial é um processo contínuo, alimentado pelas experiências que se sucedem ao longo da vida, em áreas diversificadas e com diferentes atores sociais.

A educação infantil, ao promover experiências significativas que envolvam a imaginação, a capacidade de fazer de conta e de representar usando diferentes linguagens, dentre elas a leitura, a escrita, a dramatização e as artes plásticas, e outras mais poderá trabalhar na perspectiva da formação da identidade e da diversidade étnico-racial. Por meio da brincadeira, dos jogos de faz de conta, a criança aprende a conhecer a si mesma e também ao outro. Ao inventar modos de ser, ela compreende as múltiplas possibilidades de se constituir como sujeito e respeitar o outro.

Os jogos de faz de conta expressam concepções, como registra a pesquisa de Picollo (2007).

Excerto 1R: Um grupo de seis meninas dramatizava uma brincadeira de casinha pelo parque, sendo que durante uns 20 minutos não se observou qualquer desentendimento entre elas. Entretanto, quando as meninas resolveram trocar as funçôes sociais ocupadas por cada uma na dramatização (cozinheira, patroa, filha, médica, dentista e cabeleireira), a antiga calmaria deu lugar a conflitos e discussões, [...] Júlia (loira) 
achava que não havia qualquer fundamento em Jennifer querer ser médica ou cabeleireira (funções pretendidas por ela), na medida em que "não havia médicas negras, além disso, como ela poderia ser cabeleireira com um cabelo tão feio" (palavras de Júlia) (PICCOLO, 2007, p. 142).

Não foi por mero acaso que foi vetada à menina negra a possibilidade de ser médica ou cabeleireira. Tais ações ocorrem mais do que gostaríamos nas salas de educação infantil, colaborando de modo negativo na construção da identidade das crianças, por isso é importante que a professora fique sempre atenta a esse tipo de situação, tal como está posto no Art. $7^{a}$ inciso V da DNCEI a pedagogia deve cumprir sua função sociopolítica e pedagógica:

$\mathrm{V}$ - construindo novas formas de sociabilidade e de subjetividade comprometidas com a ludicidade, a democracia, a sustentabilidade do planeta e com o rompimento de relações de dominação etária, socioeconômica, étnico-racial, de gênero, regional, linguística e religiosa (grifo nosso).

Sobretudo, é parte do trabalho desenvolvido pela professora a oferta às crianças de múltiplas possibilidades que ampliem seus repertórios de compreensão da realidade social. Para os bebês e crianças pequenas, especialmente, esse trabalho é fundamental. Brincar, relacionar-se com outras crianças e ter em conta que elas devem ser de diferentes grupos étnicos e raciais é proporcionar a elas a vivência da igualdade racial. Os jogos simbólicos, os objetos que compõem os ambientes educacionais, os bonecos e bonecas, os móbiles, fantoches, enfim, tudo que colocarmos à disposição dos pequenos pode ter um caráter que lhe envolvam numa lógica da diversidade que lhes propicie a construção cognitiva e simbólica da igualdade.

Tanto para o desenvolvimento da linguagem oral como da linguagem escrita, a atividade de contar histórias ocupa um lugar de destaque. Nesse sentido, vale identificar as pessoas do bairro que são consideradas boas contadoras de causos e convidá-las a participar das aulas. Chamar avós de diferentes gerações para que contem histórias de sua infância para as crianças - sempre 
tendo o cuidado de trazer pessoas que representem a diversidade étnico-racial - será atividade muito agradável. Também cabe aqui o convite aos militantes de grupos sociais, especialmente nesse caso negros e indígenas, para que contem histórias de suas vidas. Pode-se, ainda, convidar clubes ou associaçôes que se reúnem a partir do critério de etnicidade ou raça. Essas pessoas e grupos darão um sabor e um ritmo especial aos momentos dedicados ao desenvolvimento da linguagem, oral e escrita; eles poderão ensinar cantos típicos, de seu tempo ou grupo, parlendas, ditados etc.

Em ambas as habilidades é preciso criar um espaço para a literatura. Ela será o veículo no qual as crianças tomarão contato com contos, lendas, mitos e histórias africanas e indígenas. Achamos muito natural que as crianças brasileiras conheçam a história da Chapeuzinho Vermelho, dos Três Porquinhos, do Gato de Botas etc., todos eles contos de culturas europeias. Porém, não nos questionamos quanto à ausência de contos de origem africanas e indígenas, povos com presença tão forte em nosso cotidiano.

Por isso, trabalhar na perspectiva da diversidade étnicoracial é trazer para o ambiente da educação infantil, além dos contos tradicionais largamente trabalhados nessa etapa, novas referências de produção literária e oral. Vamos contar para nossas crianças outras histórias: Caçadores de Aventuras, contos africanos ou a história dos Reizinhos de Congo. Há caminhos para enriquecer o universo infantil com referenciais de literatura que vão além dos europeus, o que precisamos é estar alertas quando realizamos nosso planejamento para que a riqueza dessas produções não seja ignorada.

O trabalho de leitura e de contar histórias também deve ser realizado com os bebês, não para alfabetizá-lo, no sentido tradicional dado à palavra, mas porque eles também têm direito de acessar essas modalidades de linguagem é o que chamamos de letramento; eles podem e devem vivenciar a função social da escrita e da leitura. Tanto eles como as crianças bem pequenas se interessam por narrativas lidas ou contadas, se divertem com os sons que 
emitimos ao contar histórias para eles, apreciam as ilustrações, os tamanhos e formatos dos livros, assim como podem interagir com as várias possibilidades que esses materiais vêm apresentando e neles também a diversidade racial deve se apresentar.

A presença na educação infantil de literatura com personagens negros representados positivamente e de histórias indígenas colabora para que a criança valorize os diferentes sujeitos, percebendo que não há apenas um tipo de beleza, um grupo ou um continente que é capaz de produzir conhecimento. As rainhas e as princesas que povoam o imaginário de nossas crianças vão além da Branca de Neve e Rapunzel ao encontro também de outras princesas negras, de outros saberes e sabores que habitam o reino infantil.

\section{Experiências de interação com elementos do patrimônio cultural brasileiro com ênfase na igualdade racial}

Algumas instituições ainda centram muitas de suas atividades em datas comemorativas. Embora acreditemos que algumas devam ser trabalhadas, consideramos que nem todas precisam fazer parte do calendário de práticas das crianças dessa etapa. Também acreditamos que o modo como elas estão presentes necessita ser repensado. Colocar crianças para pintarem desenhos prontos referentes ao Dia do Soldado, Dia das Mães, dos Pais, Dia do Índio, Dia da Primavera e Páscoa, dentre outros, sem produzir nenhuma reflexão sobre os temas não é um trabalho pedagógico e sim, a perpetuação na educação infantil de uma educação centrada na memorização e nas aprendizagens sem significado. Apesar de certas ocasiões comemorativas propiciarem aberturas para propostas criativas de trabalho, muitas vezes os temas não ganham profundidade e nem o cuidado necessário, acabando por difundir estereótipos culturais e pouco favorecendo a construção de conhecimentos sobre a diversidade de realidades sociais, culturais, geográficas e históricas.

Muitas vezes a professora dedica horas e horas de seu trabalho preparando as chamadas "lembrancinhas" ou ensaiando 
nervosamente as crianças para apresentações exaustivas, quando poderia utilizar esse tempo para pensar como sua prática poderia oportunizar que as crianças se apropriem de elementos da cultura de sua comunidade, por meio do acesso a espaços culturais diversificados, entrando em contato com apresentaçôes musicais, teatrais, fotográficas e plásticas, visitas a bibliotecas, brinquedotecas, museus, monumentos, equipamentos públicos, parques, jardins, ou seja, estabelecer um contato real com o patrimônio cultural brasileiro.

Pensar experiências de aprendizagem envolvendo o patrimônio cultural é tão rico para trabalhar a diversidade étnico-cultural na educação infantil, como um valor positivo, que por mais proposições que façamos não será possível abarcar minimamente todas as possibilidades que esse tema traz.

\section{Organização dos grupos e seu modo de ser, viver e trabalhar, os lugares e suas paisagens, objetos e suas transformações, os seres vivos e os fenômenos da natureza}

Uma das experiências de aprendizagem importantes para crianças nessa faixa etária consiste em estimular a participação em atividades que envolvam histórias, brincadeiras, jogos e canções que digam respeito às tradições culturais de sua comunidade e de outros grupos. Esse trabalho implica, também, o conhecimento de seus pares e suas histórias, saber de onde veio o seu amigo, conhecer histórias da vida de sua colega.

Relacionar as profissões e os saberes que pais, avós, tios e outros parentes reúnem faz parte desse tópico e proporciona às crianças muitas informaçôes que as ajudarão a compreender a diversidade de pessoas que as cercam. Por que há muitas pessoas de origem asiática trabalhando com vendas, por exemplo, e por que outros grupos de origens diferentes trabalham com coisas diferentes? Esse é um tema que abre margens a muitas abordagens e estimula a conhecer o outro. 
As crianças poderão construir maquetes para representar as diferentes paisagens de lugares da África, rompendo com a ideia mais divulgada na mídia de que este seja apenas um continente devastado. Pode-se, também, mostrar vídeos, fotos e filmes, nos quais os lugares e as paisagens sejam diferentes, possibilitando que compreendam o continente africano em toda a sua riqueza, em diferentes épocas. Poderão produzir desenhos comparativos entre Brasil e África. Turmas diferentes podem realizar projetos com lugares e paisagens distintas e depois trocarem entre si seus conhecimentos.

No que se refere aos objetos e suas transformações também aqui se pode realizar trabalhos comparativos sobre a utilização de um objeto, por exemplo, os talheres - quais culturas usam talheres ou que tipo de objeto é utilizado para a alimentação? São sempre iguais? Por que são diferentes? Em que são diferentes? Sempre foram do mesmo jeito? As mesmas perguntas podem ser feitas sobre instrumentos musicais.

As experiências de aprendizagem que tratam do continente africano são excelentes oportunidades para verificar os efeitos que o trabalho com a igualdade racial vem produzindo, pois ao abordar este assunto a professora poderá observar as reações, coletar ideias sobre os diferentes povos e, se necessário, produzir intervenções a fim de reforçar atitudes em favor da igualdade racial, verificando o quanto está fortalecida a percepção da igualdade de direitos entre elas e identificando quais são, ainda, as necessidades dos integrantes do grupo para melhorarem seus conhecimentos sobre o tema e adquirirem uma atitude positiva diante das diferenças raciais.

\section{Jogos e brincadeiras com noções matemáticas}

Algumas experiências de aprendizagem relacionadas às noções matemáticas podem ser abordadas com o olhar da igualdade racial. Podem ser apresentados os desenhos africanos e suas formas geométricas. Essas formas estão presentes no cotidiano dos povos africanos, nos penteados, nos desenhos dos tecidos, 
nas pinturas e esculturas, na produção do artesanato, em jogos e brincadeiras, mesmo na simbologia religiosa e na representação dos valores.

E ainda os jogos de tabuleiros, que são diversos na cultura dos povos africanos e que auxiliam na formulação de hipóteses: realizações de cálculos, utilização de instrumento de medição, ordenação e quantificação de grandezas, entre outros.

\section{Finalizando?}

Sabemos que este documento não esgota as múltiplas possibilidades de construir uma proposta pedagógica da educação infantil que contemple a igualdade racial, mas acreditamos que as possibilidades aqui apresentadas possam colaborar com os professores e gestores para implementarem as Diretrizes Curriculares Nacionais para a Educação Infantil e as recomendações contidas no Parecer/CNE/CEB n²0/2009, transformando o texto em letra viva, ou melhor, em experiências de aprendizagem vividas pelas crianças desde bebês.

Não poderíamos finalizar sem enfatizar que a formação de professores da educação infantil em âmbito inicial ou continuada tem de garantir que o tratamento da diversidade e a perspectiva de promoção da igualdade se façam presentes, pois as proposições aqui apresentadas não têm uma perspectiva ingênua que ignore as condições estruturais da sociedade como geradoras da desigualdade racial e acredite que a sociedade igualitária será produzida por mudanças meramente pedagógicas, o compromisso se revela nas práticas, mas a luta por igualdade se dá em diferentes frentes, é uma luta política e, por isso, não pode prescindir do espaço de formação. 


\section{Referências}

BENTO, Maria Aparecida Silva; CARONE, Iray (Orgs.). Psicologia Social do Racismo: estudos sobre branquitude e branqueamento no Brasil. Petrópolis: Vozes, 2002.

BENTO, Maria Aparecida da S.; SILVA Jr., Hédio; DIAS, Lucimar Rosa. Educação infantil, diversidade e igualdade etnicorracial. Trabalho encomendado, 33 ${ }^{\mathrm{a}}$ reunião Anped, 2010.

BRASIL. Constituição (1988). Constituição da República Federativa do Brasil. Brasília, DF, Senado,1998.

BRASIL. Decreto n ${ }^{\circ} 63.223$ de 6 de setembro de 1968. Convenção à luta contra a discriminação no campo do ensino, adotada em 15 de dezembro de 1960, em Paris, pela $11^{\mathrm{a}}$ sessão, da Conferência Geral da UNESCO. Diário Oficial da União, Brasília, DF, 19 de julho de 1968.

BRASIL. Decreto ${ }^{0}$ 65.810, de 8 de dezembro de 1969. Convenção Internacional sobre a Eliminação de Todas as Formas de Discriminação Racial. Ratificada pelo Brasil em 27 de março de 1968. Diário Oficial da União, Brasília, DF, 10 de dezembro de 1969.

BRASIL. Decreto $n^{\circ}$ DECRETO No 6.177, de $1^{\circ}$ de agosto de 2007. Promulga a Convenção sobre a Proteção e Promoção da Diversidade das Expressões Culturais, assinada em Paris, em 20 de outubro de 2005. Ratificada pelo Brasil em 16 de janeiro de 2007. Diário Oficial da União, Brasília, DF, de 2 de agosto de 2007.

BRASIL. Decreto ${ }^{\circ}$ DECRETO No 485, de 20 de dezembro de 2006. Aprova o texto da Convenção sobre a Proteção e Promoção da Diversidade das Expressões Culturais, celebrada em Paris, em 20 de outubro de 2005. Ratificada pelo Brasil em 7 de dezembro de 2006. Diário Oficial da União, Brasília, DF, 20 de dezembro de 2006.

BRASIL. Decreto no 99.710, de 21 de novembro de 1990. Convenção sobre os Direitos da Criança. Ratificada pelo BRASIL. Decreto 99.710, de 21 de novembro de 1990. Ratificada pelo Brasil em 22 de novembro. Diário Oficial da União, Brasília, 22 novembro de 1990.

BRASIL. Lei ${ }^{\circ}$ 8.069, de 13 de julho de 1990. Dispõe sobre o Estatuto da Criança e do Adolescente. Diário Oficial da União, Brasília, DF, 16 